\title{
Safety analysis of the Żelazny Most tailings pond: qualitative evaluation of the preventive measures effectiveness
}

https://doi.org/10.2478/sgem-2021-0011

received May 7, 2021; accepted May 11, 2021.

\begin{abstract}
In this paper, a qualitative safety analysis of the Żelazny Most tailings pond is addressed. This object is one of the largest facilities of this type in the world being a crucial element in the technological line of copper production in KGHM Polska Miedź S.A. The assessment of the effectiveness of two types of preventive measures, i.e., relief wells and loading berms, is investigated based on displacement and stability analysis of two 2D crosssections in a technical section of the dam. The study shows that the considered preventive measures generally have a positive impact on increasing the safety level of the structure during its further raise. In particular, their effectiveness is most evident when they are applied simultaneously. It is eventually suggested that the selection of final solutions to be applied on the facility should be based on the quantitative 3D analysis.
\end{abstract}

Keywords: tailings pond; dam safety; loading berm; relief wells.

\section{Introduction}

Tailings ponds play an essential role in the mining industry. The main purpose of constructing such facilities is to enable the storage of post-mining waste. Waste rock

*Corresponding author: Adrian Różański, Wroctaw University of Science and Technology, Wybrzeże Wyspiańskiego 27, 50-370 Wrocław, Poland, E-mail: adrian.rozanski@pwr.edu.pl, ORCiD: 0000-00033150-6429

Dariusz Łydżba, Maciej Sobótka, Michał Pachnicz, Szczepan

Grosel, Wroctaw University of Science and Technology, Wybrzeże Wyspiańskiego 27, 50-370 Wrocław, Poland

Matylda Tankiewicz, Wroctaw University of Environmental and Life Sciences, Norwida 25, 50-375 Wrocław, Poland

Paweł Stefanek, KGHM Polska Miedź S.A. Oddział Zakład

Hydrotechniczny, ul Polkowicka 52, 59-305 Rudna, Poland in the form of a slurry, after enriching ore in the flotation process, is brought to the pond using hydro-transport system. At the same time, tailings ponds often take an important part in mining water management systems. Ensuring the safe use and subsequent reclamation of such facilities is extremely important (Psarropoulos \& Tsompanakis, 2008; Wang, 2009) due to the continuity of the production process, but most of all lives of people, both mine employees and local inhabitants, as well as the protection of the natural environment (Wang et al., 2018). At the same time, ensuring the safety of such facilities is a difficult and complex task in practice (Golestanifar \& Aghajani Bazzazi, 2010). This is indicated by the records of numerous failures that have taken place all over the world in recent decades (Blight, 1997; Moxon, 1999). Moreover, since mine tailings dams are among some of the world's largest engineered structures (Owen et al., 2020), the scale of damage due to dams' failures is huge. These facts emerge the necessity to take every effort to ensure the safety of such objects. This should be done through appropriate design, based on precise geotechnical investigations and computational analysis particularly concerning the stability verification as well as continuous monitoring (Wang et al., 2011). Results of the latter can be also used to verify the efficiency of computational models.

Dams are subsequently raised during the exploitation of tailings ponds. They are formed using locally extracted material, e.g., coarse waste from tailings. Furthermore, tailings are deposited with a significant amount of effluent discharge and must be drained properly. These features significantly distinguish tailings dams from other types of retention structures, e.g., water reservoirs. In addition to that, according to Rico, Benito, \& Diez-Herrero (2008) and Rico, Benito, Salgueiro, et al. (2008), the following characteristics make tailings dams more vulnerable to safety issues: lack of regulations on specific design criteria; lack of dam stability requirements regarding continuous monitoring and control during construction 
and operation; and high cost of maintenance works for tailings dams after closure of mining activities.

Due to the specifics of tailings dams' operation, their safety factor gradually decreases as the elevation of the tailings rises (Ozcan et al., 2013). Thus, the height of the dam states one of the critical factors affecting the stability (Golestanifar \& Aghajani Bazzazi, 2010). This factor must be taken into account in stability analyses. Furthermore, as stated in Rico, Benito, \& Diez-Herrero (2008) and Rico, Benito, Salgueiro et al. (2008), failures on active facilities occur much more frequently than on inactive ones. Moreover, there are no failures at all reported on maintained decommissioned dams in Europe. Therefore, special attention should be paid in the analysis to the timedependent effects. Apart from the increase in the height of the structure itself, it is necessary to take into account the non-stationary state of filtration, in particular, pore pressure distribution within the sediments themselves, as well as the dam body and the subsoil (Jiang \& Tang, 2015; Li et al., 2009; Sitharam \& Hegde, 2017). Stability is affected by the pore pressure (Martin \& McRoberts, 1999), in particular, the water table localization (Dong et al., 2017; Tang et al., 2016; Yin et al., 2011). It is also very important to correctly determine the parameters of waste and substrate, which constitute input data for the stability verification calculations.

In this paper, a safety analysis, in the qualitative sense, of the Żelazny Most tailings pond is carried out. This object is located in southwestern Poland and is an extremely important facility for the further development of an international corporation KGHM Polska Miedź S.A. The assessment of the effectiveness of two types of preventive measures, i.e., relief wells and loading berms, is performed. The study concerns only one section of northern dam, in particular, its two 2D cross-sections. The purpose of the analysis is to obtain a qualitative assessment whether the technological measures applied in this area meet the assumptions with respect to the increase in the level of the dam safety. These are not quantitative analyses that give a specific assessment of the increase of the dam safety, and therefore, these results cannot be implemented on site. This paper is organized in a following way. Next section provides the characteristics of the facility. Subsequently, the geological conditions are discussed. The preventive measures, i.e., loading berms and relief wells being executed in the facility, are described briefly in Section 4. FE models used in the study are described in Section 5. Results presented in Section 6 are split into two subsections: prediction of displacements and stability analyses. Final conclusions (in Section 7) end the paper.

\section{Characteristics of the facility}

The Extraction Waste Neutralization Facility Żelazny Most is a crucial element in the technological line of copper production in KGHM Polska Miedź S.A. It is used to store the copper flotation waste from the ore concentration plant. The reservoir is surrounded on all sides by earth dams, which, due to their location in relation to the world, are divided into the eastern, southern, western, and northern parts. Żelazny Most is located in Lower Silesia Voivodeship in two counties: Polkowice and Lubin, $2 \mathrm{~km}$ to the west of the town of Rudna. Its construction began in 1974, and its exploitation and simultaneous expansion has been ongoing since 1977.

The Żelazny Most Tailings Storage Facility (TSF) (Fig. 1) is currently the only one location storage copper tailings for all of the mines of KGHM Polska Miedź S.A. It occupies the area of about 1600 ha. The total length of the dams in axis of the facility is about 14.3 kilometers with maximum height of over 70 meters, which makes it one of the largest tailings management facilities of its type in Europe. TSF Żelazny Most is located in southwestern Poland, near the cities Polkowice, Lubin, and Głogów, about 80 kilometers from Wrocław. An important role in the selection of the location was the possibility of using the natural depression of the terrain (the valley of the Kalinówka River) in the southeastern region of the Dalkowskie Hills.

The dams are formed by upstream method in layers with a thickness of 2.5 meters within each of 26 spigotting sections. Spigotting on the beach is carried out with the use of pipelines running around. The pond is located in the center of the facility. Its depth is about 4 meters. Currently, about 660 million cubic meters of tailings is stored. The volume of the water in the pond varies between 7 and 10 million cubic meters. The most important parameters of facility are summarized in Table 1.

The two basic functions that the facility performs since its beginning are collecting the tailings from copper ore flotation mined by KGHM Polska Miedź S.A. and retention of the technological water for the purposes of flotation process and hydrotransport.

At the Żelazny Most tailings pond, the tailings from three processing plants combined into one is stored. It is delivered by independent pipelines. The tailings are transported to the facility in the form of a lowconcentrated suspension where are distributed through washing pipelines placed on the crest of the dam. After clarification in the pond, the water is returned to plants.

Coarse-grained waste from Lubin and Rudna mines are spigotted with pipelines with a diameter of 800 millimeters placed on the crest of the dams. The 


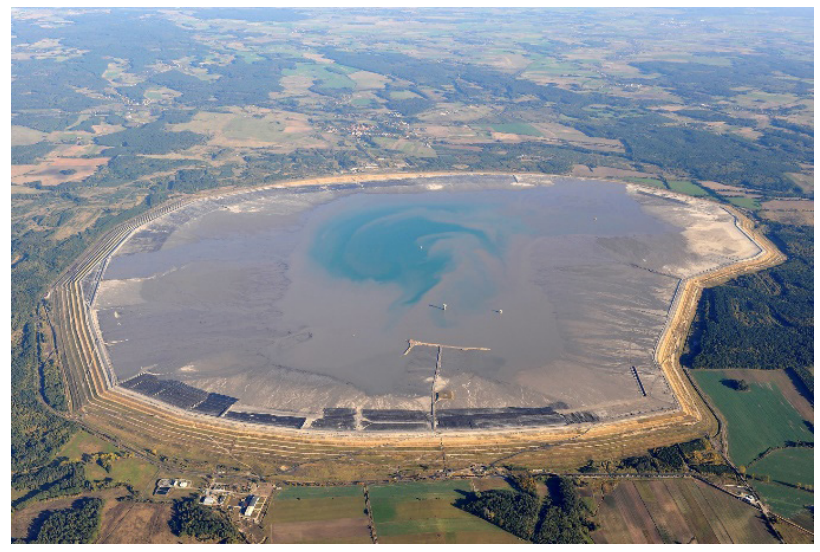

Figure 1: TSF Żelazny Most.

Table 1: Technical parameters of TSF Żelazny Most (last update in September 2020).

\begin{tabular}{lll}
\hline Parameter & Value & Unit \\
\hline $\begin{array}{l}\text { The volume according to the } \\
\text { damming curve }\end{array}$ & 660.0 & $\mathrm{mln} \mathrm{m} \mathrm{m}^{3}$ \\
Water volume & 8 & $\mathrm{mln} \mathrm{m}{ }^{3}$ \\
Tailings volume & 652 & $\mathrm{mln} \mathrm{m}{ }^{3}$ \\
Pond water elevation & 184.50 & $\mathrm{~m} \mathrm{a.s.l.}$ \\
$\begin{array}{l}\text { The crest elevation } \\
\text { The area of the TSF Żelazny Most } \\
\text { (Main Object) with infrastructure }\end{array}$ & $\sim 1580$ & $\mathrm{~m}$ a.s.l. \\
$\begin{array}{l}\text { The area on the inner side of the } \\
\text { crest }\end{array}$ & 1180 & ha \\
The reservoir area & & ha \\
Beach area & 560 & ha \\
The dam length in axis & 620 & ha \\
The height of the dams & 14,330 & $\mathrm{~m}$ \\
\hline
\end{tabular}

spigotting is carried out by sections with a length of approximately 500 meters (the facility is divided into 26 spigotting sections). In this way, beaches with a slight slope of approximately $1 \%$ toward the pound are created. Fine-grained waste from Polkowice mine is directed to the center of the facility through pipelines located on piers placed perpendicular to the dams. During the winter while the temperature is low, also coarse-grained waste from Lubin and Rudna is dumped into the central part of the facility. This type of disposal system allows for the natural segregation of waste on the beach and the use of coarse-grained material for the construction of the dams instead of natural soil (e.g., sand) which is normally used for dam construction.
Designing, constructing, expanding, and functioning of the facility are carried out on the basis of observational method, consisting in systematic verification and updating of assumptions and design solutions based on the results of observations test and measurements acquired during the operation of the facility. The use of the observation method allows the implementation of necessary changes related to ensuring the required level of safety, which are the result of the changing needs of users or the technology development at every stage of the facility's operation.

\section{Geological conditions}

Żelazny Most tailings pond is located in a natural depression in the south-central part of the Fore Sudetic Monocline. It is a Permian-Mesozoic structural unit characterized by a complex geological structure. The subsoil of the facility, together with nearby areas, was formed as a result of the South-Polish and Middle-Polish glaciations. The geological structure should be considered as complicated due to the glaciotectonic and periglacial processes that occurred in this area. The overlapping of the glaciers caused repeated accumulation of the subsoil layers and their deformation.

From the north, the landfill is surrounded by the climax of the Dalkowskie Hills (128-150 m a.s.l.). In the southern direction, in the area of the eastern dam, the land is gently lowered, and the dam crosses the valley of Kalinówka River that runs in the direction W-E under the pond. From the south, the morphology of the area is marked by the Polkowice Hills, which are the southern part of the Dalkowskie Hills, with ordinates of the highest altitude reaching over $200 \mathrm{~m}$ a.s.l. In the surroundings of the western dam, the hills gently descend again to 125-130 m a.s.l. in the area of the Kalinówka River valley. The majority of the area of Żelazny Most is located in the catchment area of the Kalinówka, which is divided by dams in the east and west. Significant fragments of watercourses occurring in the area of the present-day reservoir have been excluded from their natural catchment area and included in the artificial drainage system.

The main subsoil of the reservoir is represented by Cenozoic sediments that consists generally of Neogene and Quaternary: Pleistocene and Holocene. Locally also occur solifluction deposits. These layers have a significant importance for the safety of the foundation and operation of the facility. The Neogene stage comprises mainly of clays and silty clays. Within the clay series, there are also silty, fine, and medium sands, usually in the form of thin layers and lenses. Clayey layers have a high plasticity 


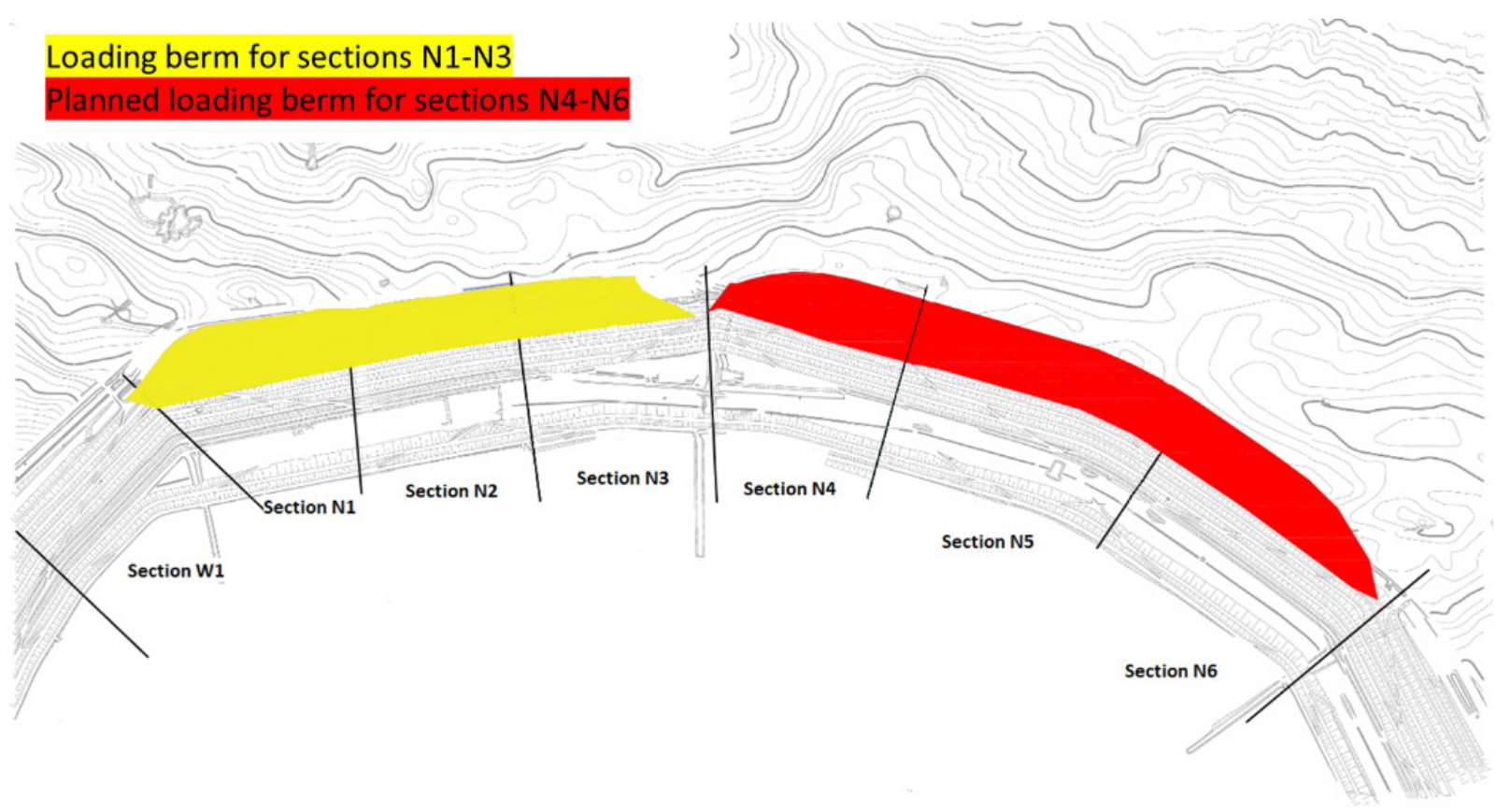

Figure 2: Loading berms on the northern dam.

index and are heavily glaciotectonically deformed. The slickensides occur at various depths and are frequent and multidirectional. Geological profiles show a number of slips of older Neogene layers over the younger Quaternary layers. Quaternary stages consist of glacial formations, i.e., tills, sandy, and glaciolacustrine sediments, as well as stagnant and Holocene sediments deposited within the river valleys. Deposits are located on the folded surface of Neogene layers. Solifluction deposits have both Neogene and Quaternary (often mixed) origins. In the subsurface zone in the glacier foreground, the source materials were subject to frost weathering. This process led to numerous cracks, disturbances, and mix-ups of layers. The Cenozoic formations: Neogene and Quaternary significantly affect the hydrological conditions of the subsoil of the facility. Their characteristic feature is the separation of stages and aquifers by a series of isolating layers. The aquifers of Neogene stage are mainly confined, while those of Quaternary in the subsurface layer are unconfined.

\section{Applied technological/preventive measures}

In recent years, the occurrence of increased horizontal and vertical deformations has been observed on the facility. To restrain them and improve dam stability, three types of technical solutions have been implemented:

- Construction of loading berms

- Installation of a relief wells system

- Moving the dam crest toward the center of the pond (during the construction of superstructure).

Two of these measures, namely, loading berms and relief wells, considered in the analyses presented later in the paper are described in detail below.

\subsection{Loading berms}

To reduce the dam displacements, the loading berm on the pond forefield was built. This procedure, according to the designer's idea, is causing an increase in the stabilizing moment (in relation to the destabilizing moment), and consequently, the overall factor of safety of the dam is increased. However, in the case of loading berms, it is necessary to use effective drainage of the subsoil. This is aimed at reducing the excess pore pressure generated by additional loading in the soil layer working without drainage. Lack of effective drainage may result in a decrease in soil strength.

In the area of the northern dam, two loading berms have been planned - in the sections N1-N3 and N4-N6. 


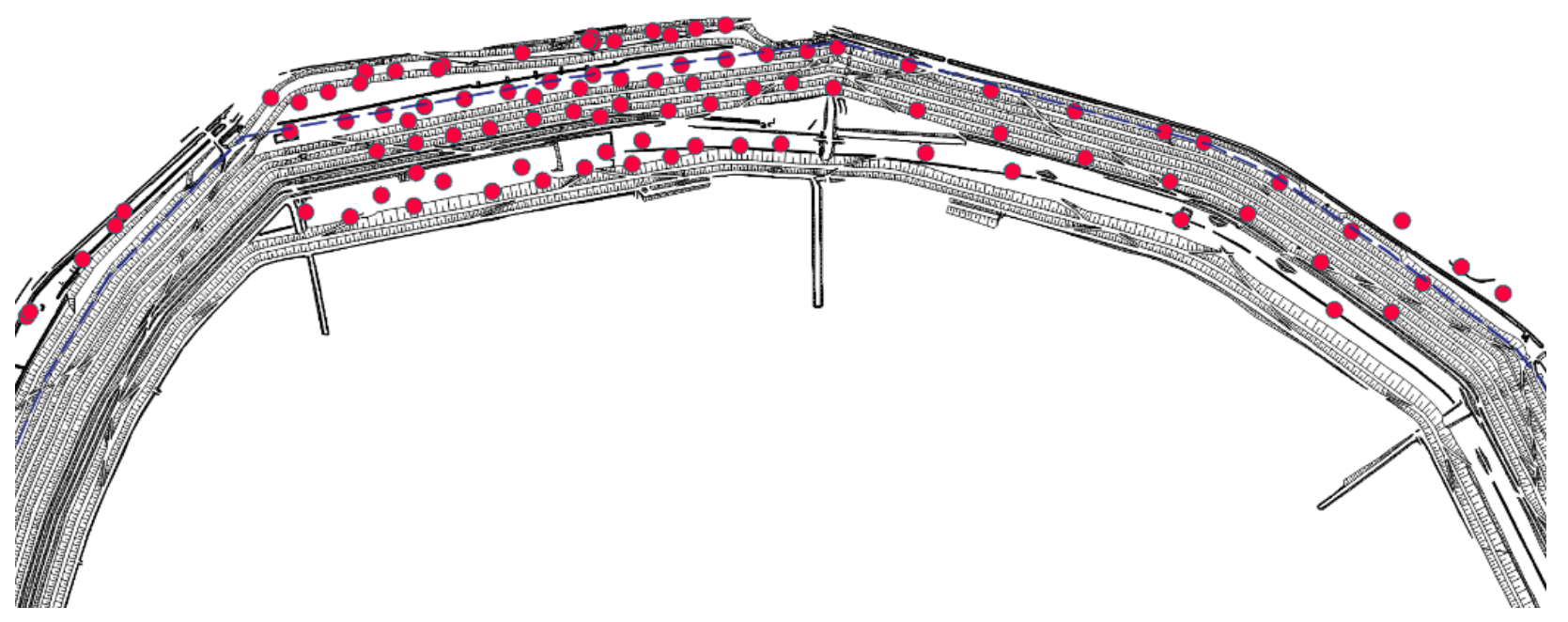

Figure 3: Locations of relief wells in the considered area.

Fig. 2 shows the location of both berms. The embankment in sections N1-N3 (yellow) was built in the period from 2013 to 2015. The one in sections N4-N6 (red) is planned in the following years (2022-2024).

Preliminary results of the monitoring carried out after the execution of the berm in sections N1-N3 indicate the effectiveness of this solution in selected cross-sections. However, at the same time, the numerical simulation is being conducted in order to verify the effectiveness of the applied preventive measures.

\subsection{Relief wells}

To mitigate the phenomenon of increasing pore pressure, a system of drainage wells (relief wells) was installed at the facility as the dam superstructure progressed. Locations of relief wells in the considered area are presented in Fig. 3.

The process of pumping water from the well must be slow, without any sudden changes in pressure (at the beginning, the water level should be lowered by $1-2 \mathrm{~m} /$ week). The upper elevation of the filter is considered a safe limit for lowering the water level. Further lowering of the water level may result in unfavorable phenomena such as erosion of silty and sandy soils. Additionally, it is important to investigate the turbidity of water pumped from wells. The process of reducing pore pressures in the object is usually a long-term task. It is due to the scale of the object and the complicated filtration conditions, which is influenced mainly by the low permeability of the Neogene clay layer.

\section{Numerical models}

The effectiveness of the measures presented in previous section was verified numerically. The finite element (FE) software used in the study, i.e., ZSoil, allows to perform calculations taking into account load varying in time as well as the staged construction of geotechnical structures (in a sequential manner). This approach was used in the case of the analyzed dam. The calculations were carried out with full hydromechanical coupling. The calculation procedure consists of the following steps:

- Creation of the geometry of numerical models, in particular, the layout of layers based on geotechnical cross sections

- Assigning material parameters throughout the problem domain and prescribing the boundary conditions (both for the problem of filtration and deformation)

- Calculation of the initial state, i.e., before dam construction, with steady-state pore pressure distribution. The displacement, deformation, and stress fields obtained in this way are treated as reference ones

- Simulation of evolution in time of displacement, deformation, stress, and pore pressure fields, which is a consequence of staged construction of the dam

- Stability calculations carried out for the individual construction stages.

The article presents an analysis of two 2D cross-sections located in technological section N5 of the northern dam (Fig. 4). The cross-sections were selected with accordance 
186 Dariusz tydżba et al.

$\$$ sciendo

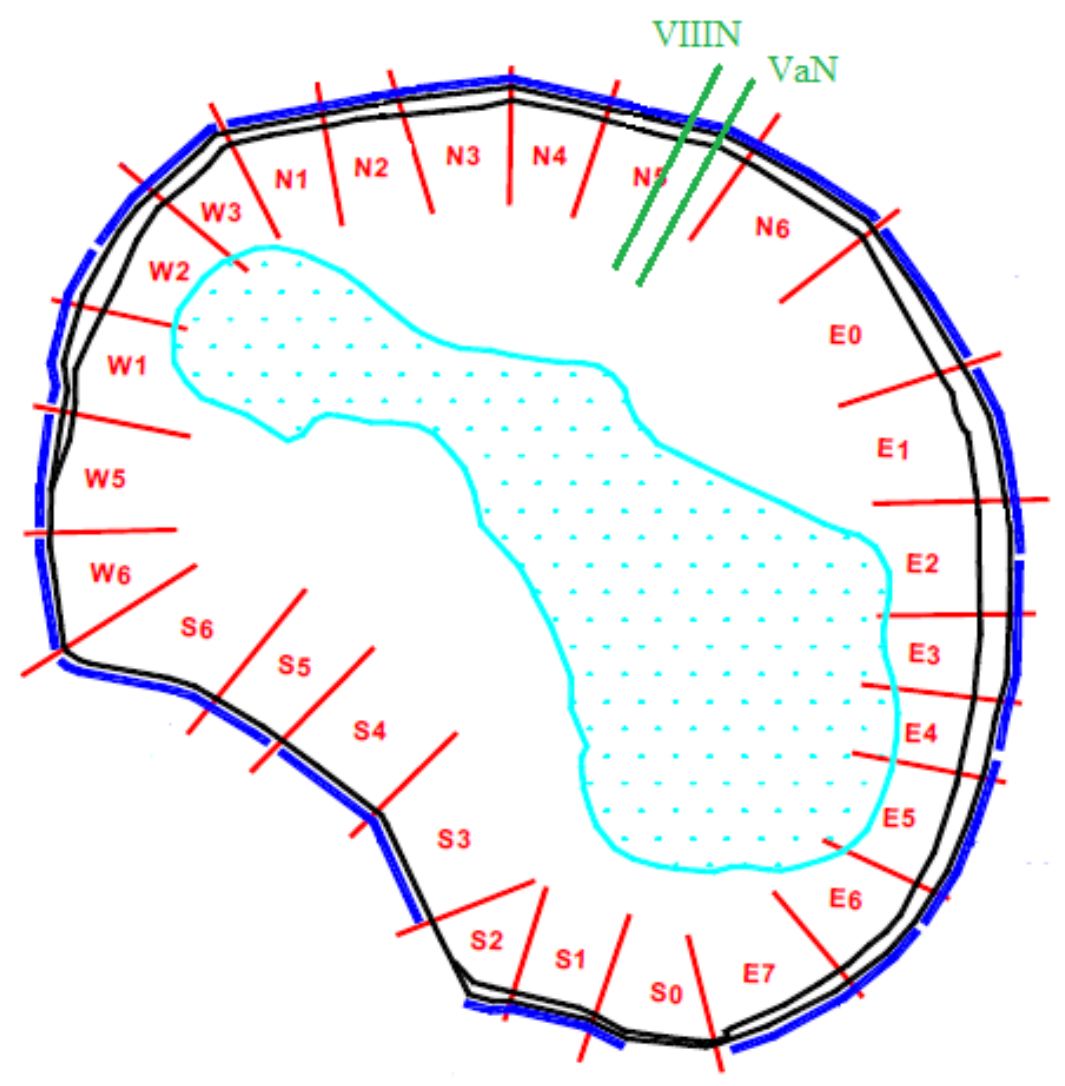

Figure 4: Technological sections (red) and cross-sections (green) selected for analysis.

a)

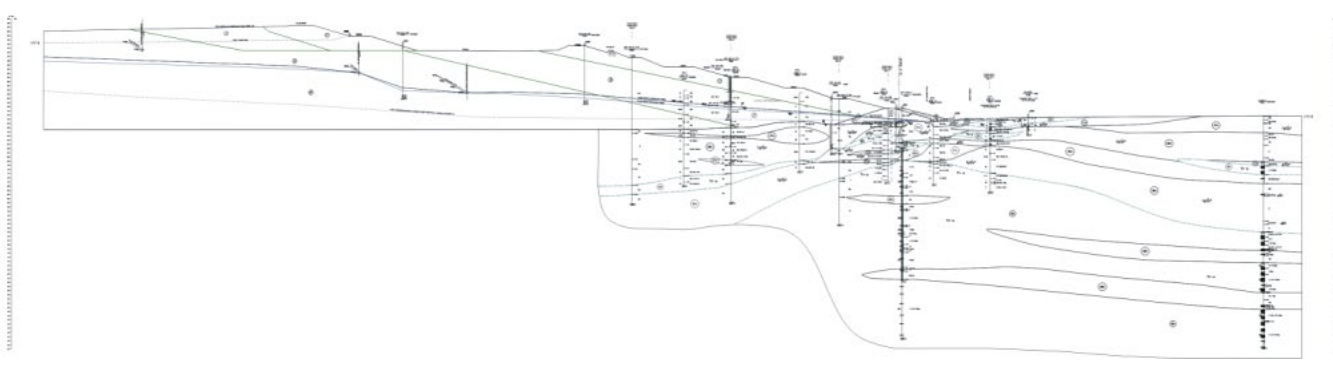

b)

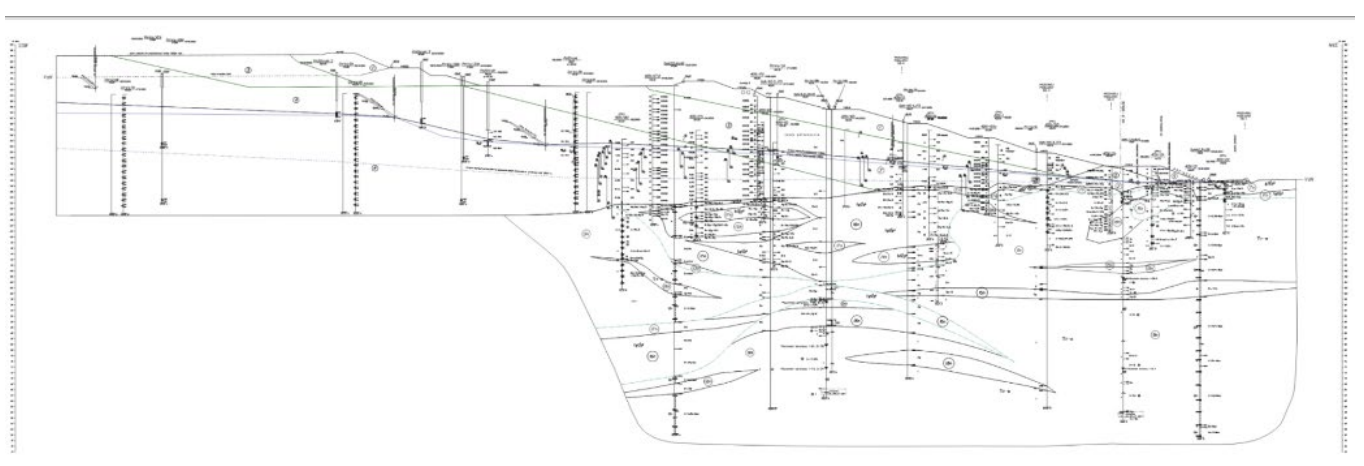

Figure 5: Geotechnical cross-sections along the boreholes located in a) cross-section VIIIN and b) cross-section VaN. 
a)

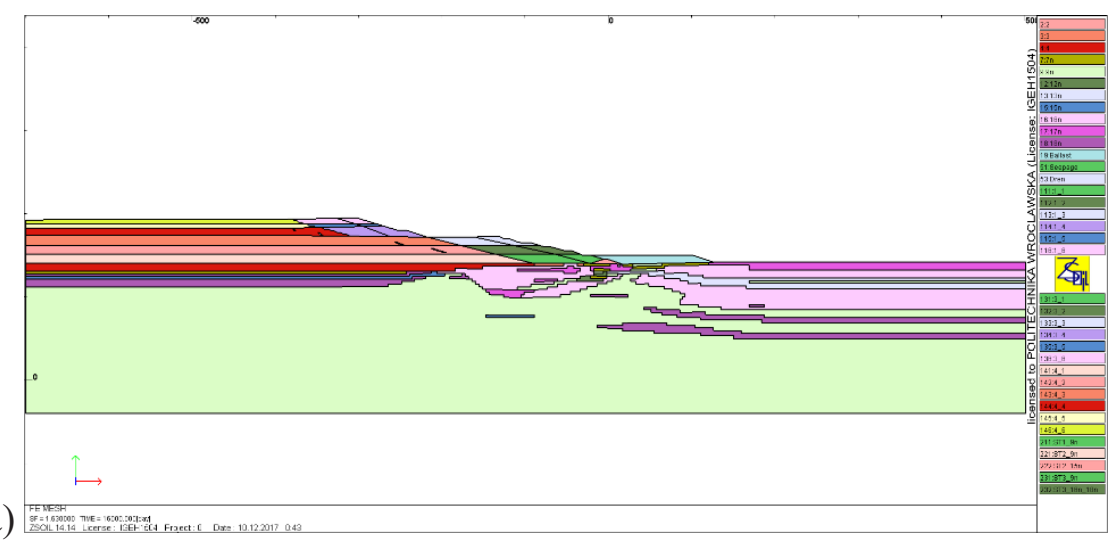

b)

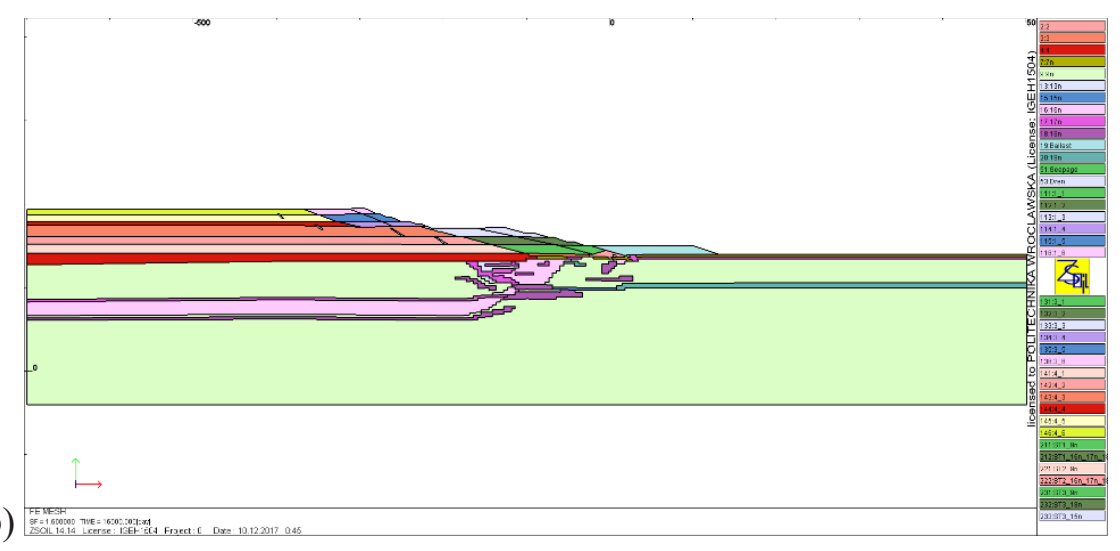

Figure 6: Numerical models of the dam with the substrate: a) cross-section VIIIN and b) cross-section VaN.

to monitoring indications, as those in which the highest rate of displacements was observed.

Geotechnical cross-sections constituting input data for calculations are presented in Figure 5, and the numerical models of the dam based on them are presented in Figure 6. As it can be seen, complex geotechnical conditions were precisely reconstructed in the model.

The progressive rise of the dam was accounted for in the numerical model. Fig. 7 shows the stages of dam elevation taken into account in the calculations (on the example of the VaN cross-section). follows:

The initial and boundary conditions were adopted as

- The hydrostatic pore pressure distribution was assumed as the initial condition, where the water table level was $140 \mathrm{~m}$ a.s.l.

- In terms of kinematic conditions, the horizontal displacements on the left and right edges of the model are fixed; degrees of freedom in both directions are fixed on the bottom edge of the domain.

- The hydrostatic pore pressure distribution was assumed on the right edge of the model and on the left edge within the sediments, and also partially on the upper surface of the domain; on the right, the level of the water table corresponding to the initial condition was assumed; on the left, the water table level corresponds to the "current" damming level in the reservoir; in a similar way, i.e., with the use of "seepage" elements, the boundary conditions within the drainage and relief wells were prescribed. The remaining part of the boundary is impermeable - the normal outward component of flux is set to 0 .

The geotechnical parameters (dry unit weight $\gamma_{d}$, unit weight at saturation $\gamma_{\text {sat }}$, angle of internal friction $\varphi$, cohesion c, dilation angle $\psi$, Young modulus $\mathrm{E}$, and Poisson ratio $v$ ) of the individual subsoil layers adopted for the numerical calculations are summarized in Table 2.

The values of the parameters presented in the Table 2 were adopted based on the geotechnical investigations and laboratory tests. Furthermore, dilation angle values were usually taken as $10 \%$ of the value of the internal friction angle. Moreover, in accordance with the recommendations of the ZSoil software (Commend et 
a)

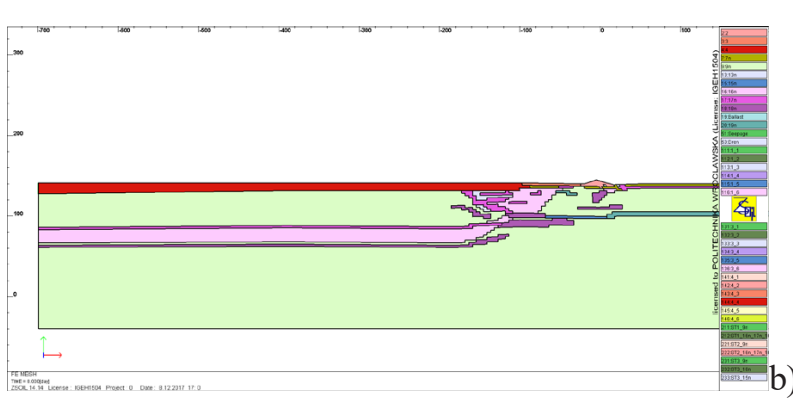

c)

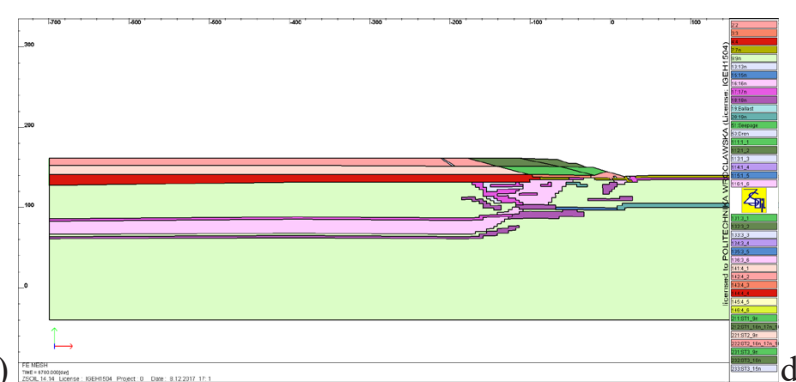

d) $=$

b)
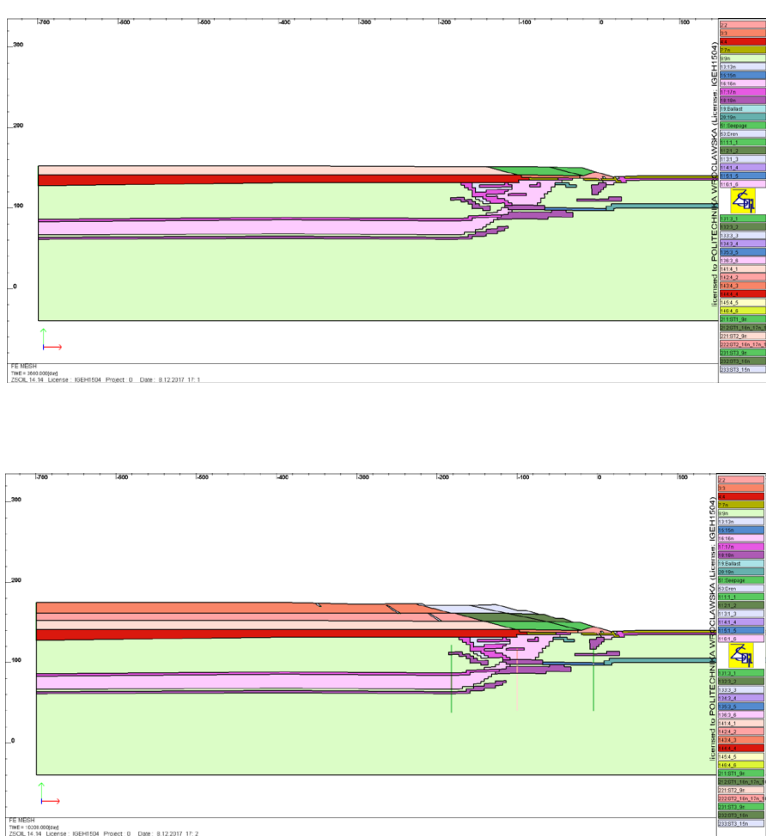

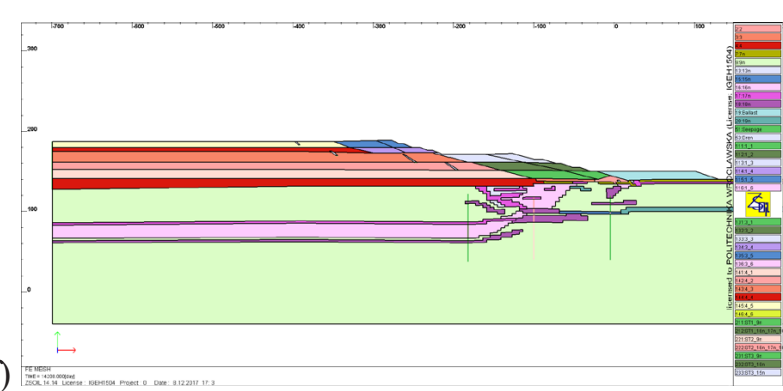

e)

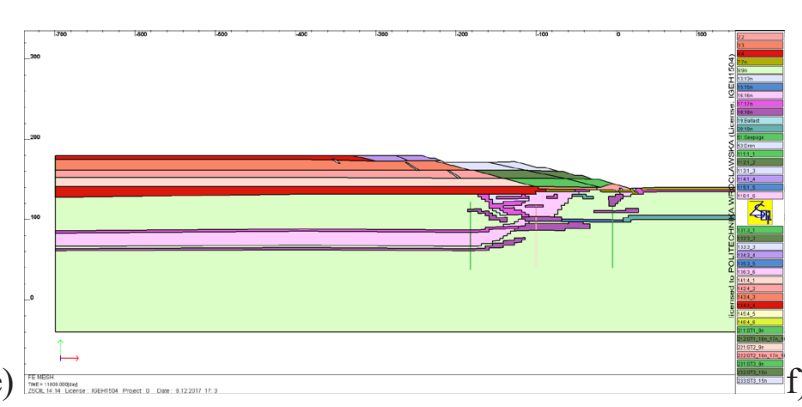

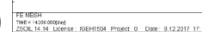

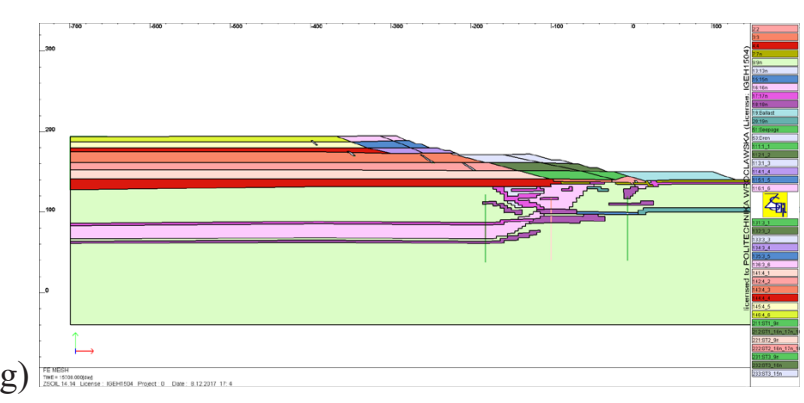

Figure 7: Geometry of the FE model in the VaN cross-section for individual stages of the dam raise, corresponding to the crest elevation [m a.s.l.]: a) 140.0 , b) 150.0 , c) 160.0 , d) 173.5 , e) 180.0 , f) 189.0 , g) 195.0.

al., 2013), in layers characterized by high values of the friction angle, the dilation angle was increased so that the difference between the friction angle and the dilation angle did not exceed $25^{\circ}$.

The data on the "dominant" layer 9n (fine-grained soils) in the subsoil come from in situ investigations reaching a depth of approximately $20 \mathrm{~m}$ below the original ground surface. As an extrapolation for greater depth, it was assumed that the deformation modulus of this layer was linearly increasing proportionally to depth. 
Table 2: Geotechnical parameters of the layers used in the calculations.

\begin{tabular}{|c|c|c|c|c|c|c|c|}
\hline Parameter & $\gamma_{d}$ & $\gamma_{\text {sat }}$ & $\varphi$ & c & $\psi$ & $\mathbf{E}$ & $\mathbf{v}$ \\
\hline Unit & {$\left[\mathrm{kN} / \mathrm{m}^{3}\right]$} & {$\left[\mathrm{kN} / \mathrm{m}^{3}\right]$} & {$\left[{ }^{\circ}\right]$} & {$[\mathrm{kPa}]$} & {$\left[{ }^{\circ}\right]$} & [MPa] & {$[-]$} \\
\hline Loading berm & 21.00 & 22.00 & 35 & 1 & 10 & 80 & 0.20 \\
\hline Dam (1) & 19.00 & 20.50 & 34 & 1 & 9 & 80 & 0.20 \\
\hline Dam (2) & 19.00 & 20.50 & 34 & 1 & 9 & 80 & 0.20 \\
\hline Beach (3) & 18.00 & 19.50 & 34 & 1 & 9 & 80 & 0.20 \\
\hline Sediments (4) & 17.00 & 18.50 & 34 & 1 & 9 & 80 & 0.20 \\
\hline Layer $7 \mathrm{n}$ & 16.06 & 20.00 & 18 & 1 & 1.8 & 96 & 0.25 \\
\hline Layer 8n & 16.06 & 20.00 & 12 & 1 & 1.2 & 100 & 0.30 \\
\hline Layer 9n & 17.30 & 20.50 & 14.5 & 5 & 1.5 & 36 & 0.25 \\
\hline Layer 10n & 16.80 & 20.00 & 10 & 1 & 1.0 & 36 & 0.25 \\
\hline Layer $12 n$ & 16.80 & 20.00 & 27 & 1 & 2.7 & 96 & 0.25 \\
\hline Layer 13n & 17.67 & 21.00 & 28 & 2 & 2.8 & 96 & 0.25 \\
\hline Layer 15n & 17.97 & 21.30 & 24 & 3 & 2.4 & 96 & 0.25 \\
\hline Layer 16n & 16.87 & 20.50 & 36 & 1 & 11.0 & 240 & 0.20 \\
\hline Layer $17 n$ & 16.06 & 20.00 & 31 & 1 & 6.0 & 240 & 0.20 \\
\hline Layer 18n & 15.86 & 19.80 & 30 & 1 & 5.0 & 240 & 0.20 \\
\hline Layer 19n & 16.80 & 20.00 & 24 & 1 & 2.4 & 96 & 0.25 \\
\hline
\end{tabular}

\section{Results}

Prior to the primary calculations, the numerical models were calibrated against the results of the measurements acquired from monitoring system working on the facility. In particular, the displacements from benchmarks, readings from inclinometers, as well as water levels from piezometers were taken into account. As a result of the calibration, the corrected set of material parameters was obtained. Examples of the revised model results together with in situ measured values are shown in Figure 8. As can be seen, the results obtained with calibrated model fit well the measurements. It is worth noting that only exemplary calibration results are presented. The calibration was carried out on a large number of results (from benchmarks, inclinometers, and piezometers). Consequently, the parameters were adopted so as to achieve the best "global" fit even though some individual results do not converge with measurements.

The purpose of the calculations (performed using previously calibrated model) was to predict the kinetics of displacements and the evolution of factor of safety with increasing dam crest elevation. In order to perform the qualitative assessment of the applied and planned technological/preventive measures, the following cases were analyzed:

- Reference case (without any preventive measures)

- Loading berm

- Relief wells

- Both preventive measures relief wells and loading berm applied simultaneously.

\subsection{Displacements prediction}

Figures 9 and 10 show the diagrams of displacement increments for the construction of the dam above the elevation of $140 \mathrm{~m}$ a.s.l. for both analyzed cross-sections. These graphs refer to the benchmark in the starting dam. The graphs show the results corresponding to the considered cases of technological measures, i.e., reference case (red dashed line), loading berm (red solid line), relief wells (blue dashed line), and both relief wells and loading berm (blue solid line). It is worth mentioning that technological measures in the form of relief wells were actually performed on the facility at an elevation of approximately $172 \mathrm{~m}$ a.s.l. In the predictions regarding loading berm, it was assumed that it would be constructed 
Benchmark pk208

a)

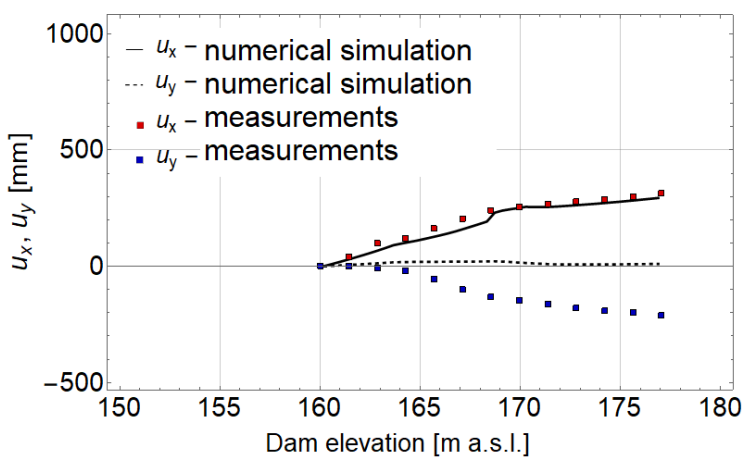

Piezometer 1_NVII-1B

b)

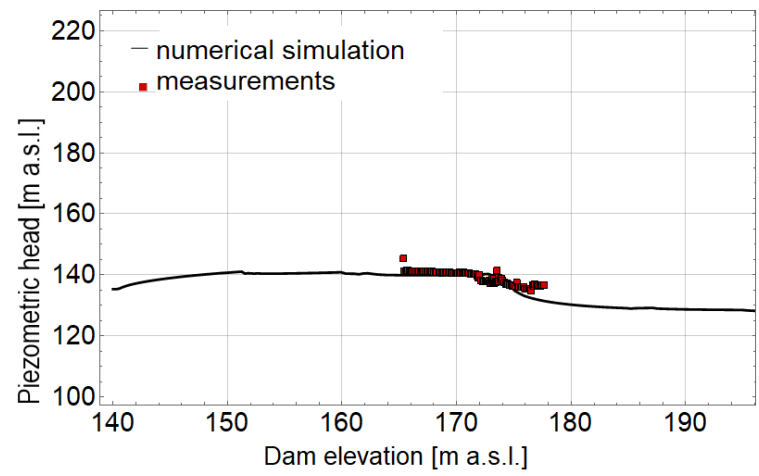

c)

\section{Inclinometer 5aN-212 (AT)}

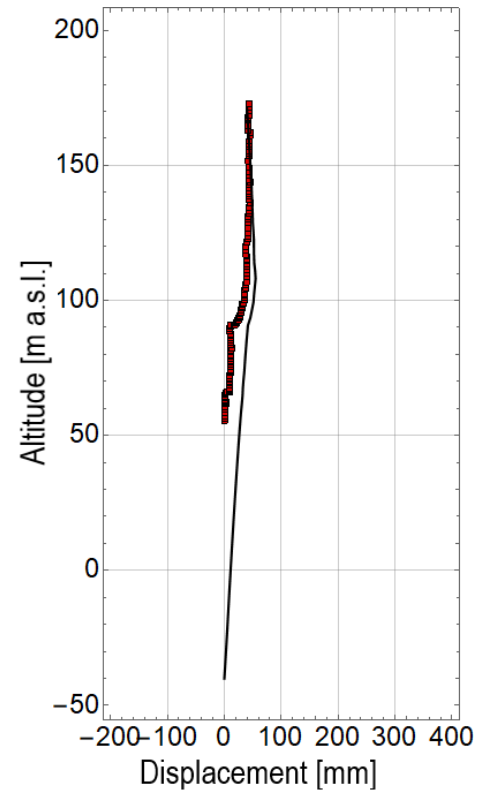

Figure 8: Exemplary calibration results: a) benchmark, b) piezometer, and c) inclinometer.

a)

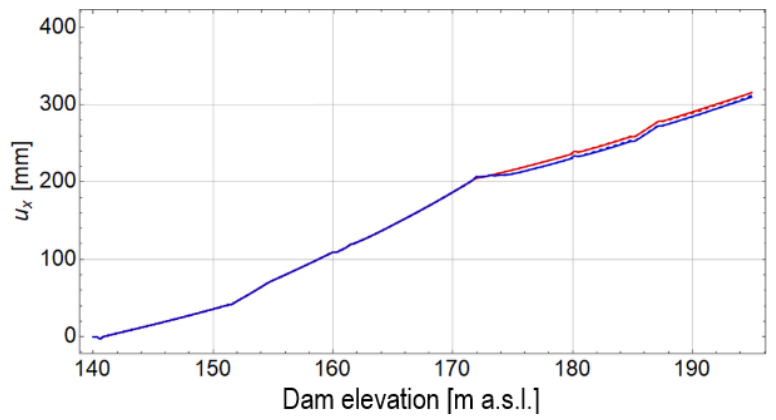

b)

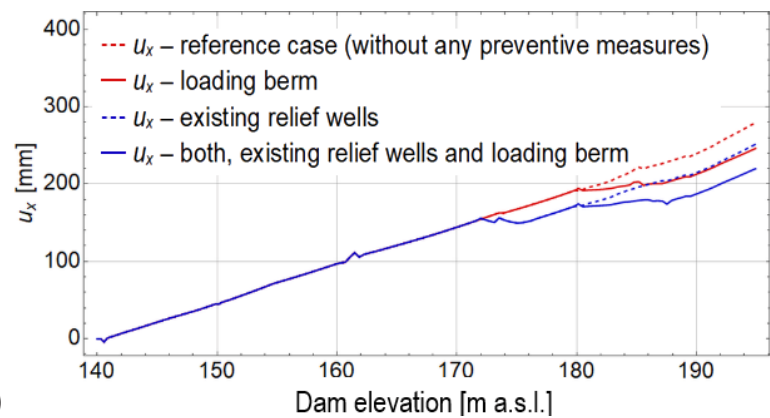

Figure 9: Horizontal displacement $\left(u_{x}[\mathrm{~mm}]\right)$ as a function of dam elevation: a) cross-section VIIIN and b) cross-section VaN.

in the period corresponding to raising the dam from 180 to $187.5 \mathrm{~m}$ a.s.l.

As it can be seen, in general, horizontal displacements are increasing in time. Technological measures, however, have positive impact on the decrease of horizontal displacement rate. The efficiency of both technological measures is more evident in cross-section VaN. In the context of vertical displacements, their general direction is upward if no technological measures are applied. The relief wells decrease the rate of these displacements. 
a)

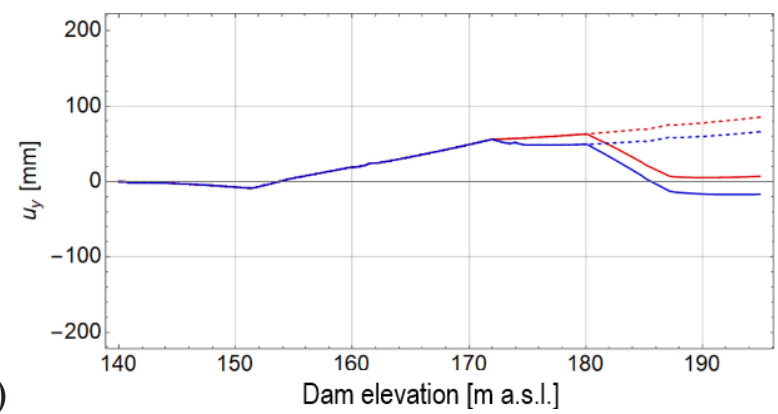

b)

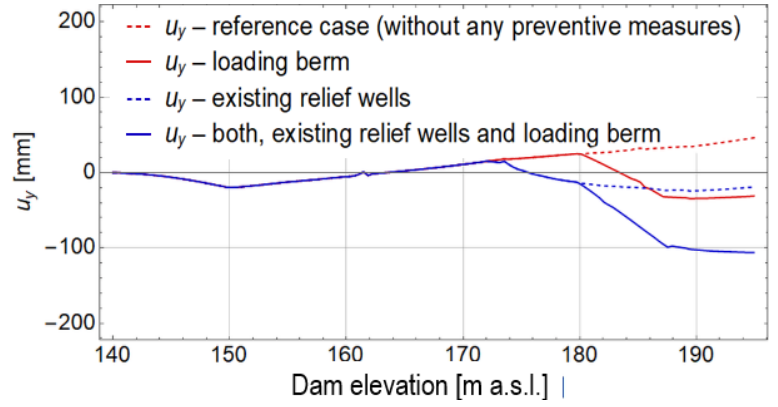

Figure 10: Vertical displacement $\left(u_{\mathrm{y}}[\mathrm{mm}]\right)$ as a function of dam elevation: a) cross-section VIIIN and b) cross-section VaN.

a)

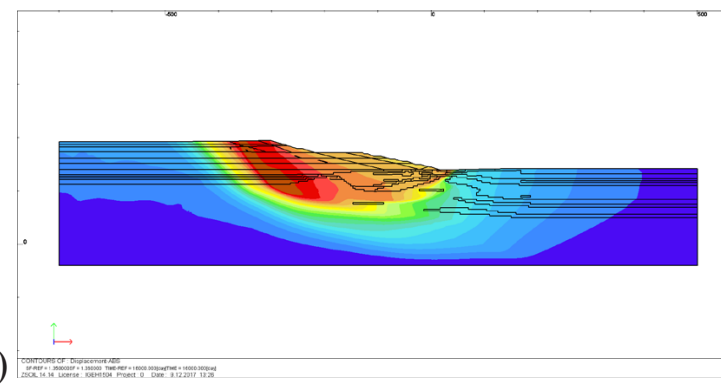

Figure 11: Potential failure mechanism for a) cross-section VIIIN and b) cross-section VaN.
The construction of the loading berm even reverses the trend causing downward displacements. Again, the more noticeable effect of the applied measures is observed for VaN cross-section.

\subsection{Stability analysis}

The stability assessment was carried out using commonly known iterative technique, called shear strength reduction (SSR) method enabling calculation of the factor of safety (FOS) in the framework of FE computations. Roughly speaking, it consists of searching for such reduction of original strength parameters of all soil layers that corresponds to the limit state. In other words, in the subsequent iterations, the parameters are reduced until a failure occurs. The failure is indicated in the numerical model by the lack of solution convergence. Detailed description of the method can be found in Lorig \& Varona (2000), Cała \& Flisiak (2001), or Cała (2007).

Figure 11 shows the displacement maps illustrating the potential mechanisms of failure corresponding to reduced parameters and the dam elevation of 195.0 [m a.s.l.].
Table 3: Factors of safety for analyzed variants.

\begin{tabular}{llll}
\hline & & FOS & \\
\hline Dam elevation & Case & VIIIN & VaN \\
180 m a.s.l. & $\begin{array}{l}\text { Reference case (without any } \\
\text { preventive measures) }\end{array}$ & 1.59 & 1.67 \\
& Loading berm & 1.59 & 1.66 \\
& Relief wells & 1.63 & 1.83 \\
& Both relief wells and loading & 1.63 & 1.83 \\
& berm & & \\
& Reference case (without any & 1.35 & 1.29 \\
& preventive measures) & & \\
& Loading berm & 1.66 & 1.58 \\
& Relief wells & 1.38 & 1.39 \\
& $\begin{array}{l}\text { Both relief wells and loading } \\
\text { berm }\end{array}$ & 1.62 & 1.59 \\
\hline
\end{tabular}

The evolutions of FOS with the dam raise (from 160 to $195 \mathrm{~m}$ a.s.l.) were calculated for all cases of preventive measures. Factors of safety values for selected dam heights of 180 and $190 \mathrm{~m}$ a.s.l. are summarized in Table 3. 
a)

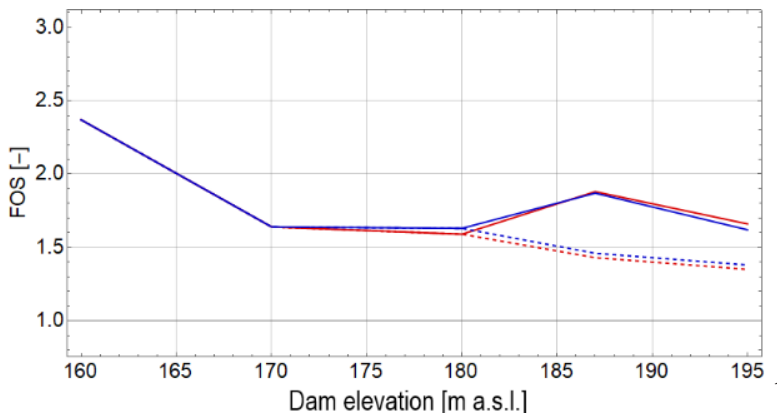

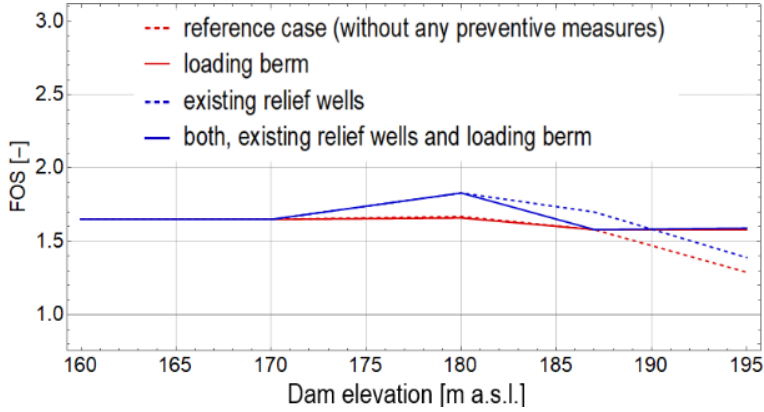

Figure 12: Evolution of FOS with the increase of the dam height: a) cross-section VIIIN and b) cross-section VaN.

In addition, plots of the evolution of the FOS as a function of the dam elevation are presented in Fig. 12.

Observing the results one can notice that without the use of technological measures, there is a trend of gradual decrease in the value of FOS when raising the dam. In case of cross-section VIIIN, installation of relief wells has a positive but minor effect on stability. The construction of loading berm evidently increases the FOS value. Referring to cross-section VaN application of relief wells noticeably improves the stability of the object. In addition, positive embankment effect is mostly evident at elevation higher than $190 \mathrm{~m}$ a.s.l.

\section{Conclusions}

A qualitative assessment of the effectiveness of relief wells and loading berms, applied on the Żelazny Most facility, was performed. Two cross-sections of the northern dam, i.e., VIIIN and VaN, were analyzed in the framework of the FE computations. The main goal of the analysis was to obtain a qualitative assessment of the preventive measures which are assumed to increase the safety level of the dam during its further raise. From performed analyses, the following conclusions can be drawn according to the two considered cross sections:

\section{Cross-section VIIIN}

- The relief wells do not affect the rate of horizontal displacement of the dam.

- Relief wells do not improve the value of the factor of safety.

- The loading berm does not affect the rate of horizontal displacements.

- The loading berm significantly improves the value of the factor of safety.
- The relief wells and the loading berm together do not have a significant impact on the rate of horizontal displacements of the dam.

- The relief wells and the loading berm together cause a significant increase in the value of the factor of safety - the impact is, however, the same as for the loading berm itself.

- Both preventive measures induce an increase in the settlement of the dam.

\section{Cross-section VaN}

- Relief wells significantly reduce the rate of horizontal displacement of the dam.

- Relief wells significantly improve the value of the factor of safety.

- The loading berm significantly reduces the rate of horizontal displacements.

- The loading berm significantly improves the value of the factor of safety.

- Relief wells and the loading berm together have the highest efficiency in reducing the rate of horizontal displacement of the dam.

- The relief wells and the loading berm applied together cause a significant increase in the value of the factor of safety - the effect is analogous to that for the loading berm itself.

- Both preventive measures induce an increase in the settlement of the dam.

The above conclusions are also summarized in Table 4:

$\checkmark$ means that a given technological measure has a positive effect on the considered feature describing the mechanical behavior of the dam, either rate of displacement or FOS.

- means that a given technological measure either does not improve or has a minor effect on the dam safety. 
Table 4: Summary of the preventive measures effectiveness with regard to safety of the dam.

\begin{tabular}{llll}
\hline Evaluated feature & Case & \multicolumn{2}{c}{ Cross-section } \\
\cline { 2 - 4 } & & VIIIN & VaN \\
\hline Horizontal displacements rate & Loading berm & - & $\checkmark$ \\
& Relief wells & - & $\checkmark$ \\
& Both & - & $\checkmark$ \\
Vertical displacements rate & Loading berm & - & - \\
& Relief wells & $\checkmark$ & - \\
& Both & - & - \\
Factor of safety (FOS) & Loading berm & $\checkmark$ & $\checkmark$ \\
& Relief wells & - & $\checkmark$ \\
& Both & $\checkmark$ & $\checkmark$ \\
\hline
\end{tabular}

The obtained results show that in the case of qualitative assessment of preventive measures efficiency, it is difficult to formulate general, unambiguous conclusions. It is mainly due to the fact that considering individual crosssection of the dam, the response of the $2 \mathrm{D}$ boundary value problem is mainly affected by the "local" arrangement of soil layers. For this reason, the obtained results cannot be directly applied as specific design solutions for the facility or its individual sections. The results should be treated only as a rough, qualitative assessment of the effectiveness of the preventive measures applied. It should be clearly emphasized that the selection of specific design solutions should be based on the quantitative results of fully 3D analyses for entire technological sections (see Fig. 4). In other words, the quantitative selection of the number, depth, spacing of wells, as well as geometry of the loading berms should be determined based on 3D models. These models should be calibrated and revised by the information from in situ measurements acquired on the facility, performed in the framework of observational method. Such approach is currently developed in the cooperation of KGHM Polska Miedź S.A. and Wrocław University of Science and Technology, and the results will be soon published.

\section{References}

[1] Blight, G. E. (1997). Destructive mudflows as a consequence of tailings dyke failures. Proceedings of the Institution of Civil Engineers - Geotechnical Engineering, 125(1), 9-18. https:// doi.org/10.1680/igeng.1997.28992
[2] Cata, M. (2007). Convex and concave slope stability analyses with numerical methods. Archives of Mining Sciences, 52(1), 75-89.

[3] Cata M., Flisiak J., 2001. Slope stability analysis with FLAC and limit equilibrium methods. FLAC and Numerical Modeling in Geomechanics (edited by Bilaux, Rachez, Detournay \& Hart), A.A. Balkema Publishers, p. 111-114

[4] Commend, S., Obrzud, R., Podleś, K., Truty, A., \& Zimmermann, T. (2013). Numerics in Geotechnics and Structures: ZSOIL. PC: getting started.

[5] Dong, L., Sun, D., \& Li, X. (2017). Theoretical and Case Studies of Interval Nonprobabilistic Reliability for Tailing Dam Stability. Geofluids, 2017, e8745894. https://doi. org/10.1155/2017/8745894

[6] Golestanifar, M., \& Aghajani Bazzazi, A. (2010). TISS: A decision framework for tailing impoundment site selection. Environmental Earth Sciences, 61(7), 1505-1513. https://doi. org/10.1007/s12665-010-0466-x

[7] Jiang, Q., \& Tang, Y. (2015). A general approximate method for the groundwater response problem caused by water level variation. Journal of Hydrology, 529, 398-409. https://doi. org/10.1016/j.jhydrol.2015.07.030

[8] Li, J., Li, C. P., Li, C. M., \& Li, Z. X. (2009). Forecasting of infiltration route in tailings dam by Support Vector Regression. Journal of Safety Science \& Technology, 5(1), 76-79.

[9] Lorig L., Varona P., 2000. Practical slope stability analysis using finite-difference codes. Slope stability in surface mining (edited by Hustrulid, McCarter \& Van Zyl), Society for Mining, Metallurgy and Exploration Inc. Littleton, p. 115-124.

[10] Martin, T. E., \& McRoberts, E. C. (1999). Some considerations in the stability analysis of upstream tailings dams. Proceedings of the Sixth International Conference on Tailings and Mine Waste, 99, 287-302.

[11] Moxon, S. (1999). Failing again. International Water Power and Dam Construction, 51.

[12] Owen, J. R., Kemp, D., Lèbre, É., Svobodova, K., \& Murillo, G. P. (2020). Catastrophic tailings dam failures and disaster risk disclosure. International Journal of Disaster Risk Reduction, 42, 101361.

[13] Ozcan, N. T., Ulusay, R., \& Isik, N. S. (2013). A study on geotechnical characterization and stability of downstream slope of a tailings dam to improve its storage capacity (Turkey). Environmental Earth Sciences, 69(6), 1871-1890.

[14] Psarropoulos, P. N., \& Tsompanakis, Y. (2008). Stability of tailings dams under static and seismic loading. Canadian Geotechnical Journal, 45(5), 663-675.

[15] Rico, M., Benito, G., \& Diez-Herrero, A. (2008). Floods from tailings dam failures. Journal of Hazardous Materials, 154(1-3), 79-87.

[16] Rico, M., Benito, G., Salgueiro, A. R., Díez-Herrero, A., \& Pereira, H. G. (2008). Reported tailings dam failures: A review of the European incidents in the worldwide context. Journal of Hazardous Materials, 152(2), 846-852.

[17] Sitharam, T. G., \& Hegde, A. (2017). Stability analysis of rockfill tailing dam: An Indian case study. International Journal of Geotechnical Engineering, 11(4), 332-342.

[18] Tang, Y., Jiang, Q., \& Zhou, C. (2016). Approximate analytical solution to the Boussinesq equation with a sloping water-land boundary. Water Resources Research, 52(4), 2529-2550. 
[19] Wang, F. Y. (2009). Research on stability analysis and comprehensive assessment of the tailing dam based on the uncertainty theory [PhD Thesis]. Ph. D. dissertation

[20] Wang, T., Zhou, Y., Lv, Q., Zhu, Y., \& Jiang, C. (2011). A safety assessment of the new Xiangyun phosphogypsum tailings pond. Minerals Engineering, 24(10), 1084-1090.

[21] Wang, X., Zhan, H., Wang, J., \& Li, P. (2018). The stability of tailings dams under dry-wet cycles: A case study in Luonan, China. Water, 10(8), 1048.

[22] Yin, G., Li, G., Wei, Z., Wan, L., Shui, G., \& Jing, X. (2011). Stability analysis of a copper tailings dam via laboratory model tests: A Chinese case study. Minerals Engineering, 24(2), 122-130. 